CLINICAL STUDY

\title{
Low TSH levels are not associated with osteoporosis in childhood
}

\author{
Anastasios Papadimitriou, Dimitrios T Papadimitriou, Anna Papadopoulou, Polyxeni Nicolaidou \\ and Andreas Fretzayas \\ Pediatric Endocrinology Unit, Third Department of Pediatrics, 'Attikon' University Hospital, University of Athens, Rinini 1, Haidari, Athens 124 62, \\ Greece \\ (Correspondence should be addressed to A Papadimitriou; Email: anpapad@med.uoa.gr)
}

\begin{abstract}
Introduction: A recent study on TSH receptor (TSHR) null mice suggested that skeletal loss occurring in hyperthyroidism is caused by the low TSH rather than high thyroid hormone levels. The aim of this study was to examine whether low TSH results in osteoporosis in the human.

Subjects and methods: We determined bone mineral density (BMD) and markers of bone metabolism in two male siblings aged 9.8 and 6.8 years with isolated TSH deficiency, due to a mutation of the TSH $\beta$-subunit gene. BMD was measured in the lumbar spine (L1-L4) by dual-energy X-ray absorptiometry. Laboratory investigation included the determination of serum calcium, phosphate, 25-hydroxyvitamin D, parathyroid hormone concentrations, and urine calcium (Ca)/creatinine (Cr) ratio. Osteoblast activity was measured by serum bone alkaline phosphatase and osteocalcin levels, and osteoclast activity by urine cross-linked amino-terminal, carboxy-terminal telopeptides of type I collagen and deoxypyridinoline concentrations.

Results: BMD of both patients was within the normal range for age and sex; $z$-scores were -0.55 and -0.23 for patients 1 and 2 respectively. Serum calcium, phosphate, urine $\mathrm{Ca} / \mathrm{Cr}$ ratio, and specific markers of bone metabolism were also within normal range.

Conclusion: In childhood, chronic extremely low TSH levels, in the face of normal thyroid hormone levels, are not related to bone loss.
\end{abstract}

European Journal of Endocrinology 157 221-223

\section{Introduction}

Several studies have shown that hyperthyroidism results in bone resorption $(1,2)$, whereas successful treatment of the disorder improves bone mineral density (BMD) (2, 3). Moreover, subclinical hyperthyroidism, i.e., suppression of thyroid-stimulating hormone (TSH) without an elevation in thyroid hormones, has also been associated with bone loss (2). These clinical situations suggested that it is the suppressed TSH rather than the elevated thyroid hormones that exert a deleterious effect on bone density. This notion was strengthened further by a recent study on TSH receptor (TSHR) null mice (4). These animals were found to be rendered osteoporotic despite thyroid extract replacement therapy, linking directly the bone phenotype to the action of TSH on bone.

Based on the TSHR null mice study, we hypothesized that if this finding was valid in humans, people with congenital TSH deficiency would be osteoporotic.

Isolated TSH deficiency is a severe form of congenital hypothyroidism that results from mutations of the gene of the TSH $\beta$-subunit. These children usually have very low levels of TSH, even as fetuses, because TSH does not cross the placenta.

In order to examine whether chronically low TSH results in osteoporosis in the human, we determined BMD and markers of bone metabolism in two male siblings with isolated TSH deficiency due to mutation of the TSH $\beta$-subunit gene.

\section{Subjects and methods}

Our patients (patients 1 and 2) are of Greek origin, aged 9.8 and 6.8 years respectively at the time of investigation. Their clinical, hormonal, and molecular data have already been reported (5). They had always had very low to undetectable TSH levels, except patient 2 who, only at diagnosis, had TSH in the low normal range despite very low thyroid hormone levels. TSH was unresponsive to thyrotropin-releasing hormone stimulation in both patients (5). Soon after birth, substitution doses of levothyroxine $\left(\mathrm{L}-\mathrm{T}_{4}\right)$ were administered with the 
therapeutic aim of keeping free thyroxine $\left(\mathrm{FT}_{4}\right)$ levels in the upper normal range for age.

BMD was measured in the lumbar spine (L1-L4) by dual-energy X-ray absorptiometry with a Hologic QDR1000 (Hologic Inc., Bedford, MA) upgraded unit and was expressed as z-scores. A BMD z-score is defined as the number of standard deviations (S.D.) below or above the mean BMD. It is calculated from the formula, (patient's BMD-mean)/s.D., where the mean and s.D. are determined using age- and sex-specific reference BMD data from healthy populations (as reference data we used those provided for Caucasians by the manufacturer of the Hologic densitometer). A patient is considered to be osteopenic if the $z$-score is between -1 and -2.5 and osteoporotic if the $z$-score is $<-2.5$.

Calcium (Ca) and phosphate $(\mathrm{P})$ in the serum and $\mathrm{Ca}$ and creatinine $(\mathrm{Cr})$ in the urine were measured using standard methods. Serum 25-hydroxy-vitamin D (25$\mathrm{OH}-\mathrm{D})$ and parathyroid hormone (PTH) levels were measured by RIA (Nichols Institute Diagnostics, San Clemente, CA, USA), as were the markers of osteoblast activity, serum bone alkaline phosphatase (BAP; Beckman Coulter, Fullerton, CA, USA) and osteocalcin (GlaOC; Myria OC; Techno Genetics, Milan, Italy). Osteoclast activity markers, urine cross-linked amino-terminal (NTX) and carboxy-terminal telopeptides of type I collagen (ICTP), were measured using RIA (Orion Diagnostica, Espoo, Finland) as well as urine deoxypyridinoline (DPD; Immunodiagnostic Systems Ltd, UK), expressed as a ratio to creatinine.

The study was approved by the Ethics Committee of 'Attikon' University Hospital and informed consent was obtained from the patients' parents.

\section{Results}

BMD of both patients was within normal range for age and sex. Patient 1 had a BMD $z$-score -0.55 and patient 2 had a BMD $z$-score -0.23 . All biochemical markers of bone turnover were normal, except urine carboxy-terminal telopeptides of type I collagen (uICTP) that were elevated in patient 1 . Laboratory findings are detailed in Table 1.

\section{Discussion}

In the present study, we evaluated BMD and markers of bone metabolism in two siblings with congenital hypothyroidism due to a $\mathrm{C}$ to $\mathrm{T}$ transition resulting in a premature stop at codon 49 (Q49stop), leading to the formation of a truncated protein (5). This disorder provided us with the ideal clinical model to test whether low TSH induces osteoporosis. Both patients had extremely low to undetectable TSH levels, in the face of normal thyroid hormone levels under $\mathrm{L}_{-} \mathrm{T}_{4}$ replacement therapy. However, despite the very low TSH
Table 1 Bone metabolism investigation in two siblings with isolated thyroid-stimulating hormone deficiency.

\begin{tabular}{lccc}
\hline & Patient 1 & Patient 2 & $\begin{array}{c}\text { Normal } \\
\text { range }\end{array}$ \\
\hline $\mathrm{sCa}(\mathrm{mg} / \mathrm{dl})$ & 9.3 & 9.9 & $8.4-11.0$ \\
$\mathrm{sP}(\mathrm{mg} / \mathrm{dl})$ & 4.4 & 4.6 & $3.5-5.6$ \\
$\mathrm{uCa} / \mathrm{Cr}(\mathrm{mg} / \mathrm{mg})$ & 0.15 & 0.17 & $<0.21$ \\
$\mathrm{sPTH}(\mathrm{pg} / \mathrm{ml})$ & 37 & 29 & $10-65$ \\
$\mathrm{~s} 25(\mathrm{OH}) \mathrm{D}(\mathrm{ng} / \mathrm{ml})$ & 25.3 & 19.8 & $10-60$ \\
$\mathrm{sBAP}(\mu \mathrm{g} / \mathrm{l})$ & 39 & 44 & $6-83.5$ \\
$\mathrm{sOc}(\mathrm{ng} / \mathrm{ml})$ & 14.7 & 13.6 & $10-50$ \\
$\mathrm{uDPD}(\mathrm{nM} \mathrm{DPD} / \mathrm{nM} \mathrm{Cr})$ & 30.8 & 32.2 & $11.4-34.4$ \\
$\mathrm{uNTX}(\mathrm{pmol} \mathrm{bce} / \mu \mathrm{mol} \mathrm{Cr})$ & 520 & 535 & $189-1056$ \\
$\mathrm{ulCTP}(\mu \mathrm{g} / \mathrm{mmol} \mathrm{Cr})$ & 1700 & 998 & $231-1238$ \\
\hline
\end{tabular}

s, serum; u, urine; Ca, calcium; $\mathrm{P}$, phosphorus; $\mathrm{PTH}$, parathyroid hormone; 25(OH)D, 25(OH) vitamin D; BAP, bone alkaline phosphatase; Oc, osteocalcin; DPD, deoxypyridinoline; NTX, cross-linked amino-terminal; ICTP, carboxy-terminal telopeptides of type I collagen.

concentrations of the patients, their BMD and markers of bone metabolism were within the normal range at the age of 9.8 and 6.8 years respectively, suggesting that TSH deficiency has no deleterious effect on BMD in the human, at least in childhood.

The confusion regarding the effect of thyroid hormones on skeletal health has a long history. The potential adverse effects of thyroid hormone on BMD in cases of suppressive rather than replacement therapy had led to management guidelines, employing the ultrasensitive TSH, in order to minimize the risk of osteopenia (6). In a study to test whether patients receiving $\mathrm{T}_{4}$ were at increased risk of osteoporosis, bone mineral densities were measured in two groups of postmenopausal women; in the first group, $\mathrm{T}_{4}$ replacement therapy resulted in persistently suppressed serum TSH levels, whereas in the second group, TSH was non-suppressed. Patients with suppressed TSH levels had a statistically nonsignificant decrease in BMD of at most $5 \%$, which was unlikely to be of clinical significance; therefore, suppression of TSH should not be an indication for reduction of $\mathrm{T}_{4}$ dose in clinically euthyroid patients (7). However, a meta-analysis of studies examining the effect of hyperthyroidism (exogenous or endogenous suppression of TSH) and thyroid hormone replacement therapy on skeletal integrity concluded that hyperthyroidism and use of thyroid hormone to suppress TSH seem to have an adverse effect on bone, especially in postmenopausal women, the largest effect being on cortical bone, and that thyroid hormone replacement seems to have a minimal clinical effect on bone (1). Moreover, accelerated bone turnover was shown to occur in women with subclinical hypothyroidism during replacement $\mathrm{L}_{-} \mathrm{T}_{4}$ treatment and normal TSH levels. In these women, bone loss was attributed to an adaptive mechanism on decreased bone turnover in pre-existent hypothyroidism (8). 
Several animal studies have addressed the subject of the effect of thyroid hormones on bone. The recent study on TSHR null mice provided evidence for direct effects of TSH on both components of skeletal remodeling, osteoblastic bone formation and osteoclastic bone resorption, mediated via the TSHR found on osteoblast and osteoclast precursors (4). Consequently, the authors suggested that the skeletal loss occurring in hyperthyroidism is due to the low TSH rather than thyroid hormone excess. In a more recent work, the same group established that osteopenia is driven by the elevated expression of the osteoclastogenic cytokine tumor necrosis factor- $\alpha$ (9). Zaidi further suggested that TSH or its receptors may be targeted for bone-specific therapy (10). Furthermore, mice devoid of thyroid hormone receptors (TR) $\alpha$ and $\beta$ have been shown to display only growth plate abnormalities instead of bone remodeling (11). Nevertheless, in a most recent study, Bassett et al. investigated the molecular mechanism of osteoporosis in thyroid disease by characterizing the skeleton in mice lacking either thyroid hormone receptor $\alpha$ or $\beta$ (12). They showed that adult TR $\beta^{-1-}$ mice, with elevated TSH and thyroid hormone levels, displayed the phenotype of osteoporosis. These data suggested that the bone loss in thyrotoxicosis is independent of circulating TSH concentrations, mediated predominantly by TR $\alpha$, which they identified as a potential novel drug target in the prevention and treatment of osteoporosis.

In hyperthyroid children and adolescents, low bone density values and high bone resorption rates have been demonstrated at diagnosis of the disease (13), suggesting that the bone during childhood is affected by the hyperthyroid state. Given the controversy regarding the role of $\mathrm{TSH}$ in the induction of osteoporosis in laboratory animals, the fact that our patients with congenital extremely low TSH levels show normal BMD and bone metabolism (except the elevated UICTP concentration in one of our patients, for which we do not have an explanation) does not favor a role for TSH in osteoporosis in childhood.

In conclusion, our data suggest that extremely low to undetectable TSH levels per se have no deleterious effects on bone density or bone metabolism in children.

\section{References}

1 Greenspan SL \& Greenspan FS. The effect of thyroid hormone on skeletal integrity. Annals of Internal Medicine 1999130 750-758.

2 Lakatos P. Thyroid hormones: beneficial or deleterious for bone? Calcified Tissue International 200373 205-209.

3 Karga H, Papapetrou PD, Korakovouni A, Papandroulaki F, Polymeris A \& Pampouras G. Bone mineral density in hyperthyroidism. Clinical Endocrinology 200461 466-472.

4 Abe E, Marians RC, Yu W, Wu XB, Ando T, Li Y, Iqbal J, Eldeiry L, Rajendren G, Blair HC, Davies TF \& Zaidi M. TSH is a negative regulator of skeletal remodeling. Cell 2003115 151-162.

5 Sertedaki A, Papadimitriou A, Voutetakis A, Dracopoulou M, Maniati-Christidi M \& Dacou-Voutetakis C. Low TSH congenital hypothyroidism: identification of a novel mutation of the TSH $\beta$-subunit gene in one sporadic case $(\mathrm{C} 85 \mathrm{R})$ and of mutation Q49stop in two siblings with congenital hypothyroidism. Pediatric Research 200252 935-941.

6 Wartofsky L. Use of sensitive TSH assay to determine optimal thyroid hormone therapy and avoid osteoporosis. Annual Review of Medicine 199142 341-345.

7 Grant DJ, McMurdo ME, Mole PA, Paterson CR \& Davies RR. Suppressed TSH levels secondary to thyroxine replacement therapy are not associated with osteoporosis. Clinical Endocrinology 199339 529-533.

8 Meier C, Beat M, Guglielmetti M, Christ-Crain M, Staub JJ \& Kraenzlin M. Restoration of euthyroidism accelerates bone turnover in patients with subclinical hypothyroidism: a randomized controlled trial. Osteoporosis International 200415 209-216.

9 Hase H, Ando T, Eldeiry L, Brebene A, Peng Y, Liu L, Amano H, Davies TF, Sun L, Zaidi M \& Abe E. TNF $\alpha$ mediates the skeletal effects of thyroid-stimulating hormone. PNAS 2006103 12849-12854.

10 Zaidi M. Low TSH triggers bone loss: fact or fiction? Thyroid 2006 16 1075-1076.

11 Gothe S, Wang Z, Ng L, Kindblom JM, Barros AC, Ohlsson C, Vennstrom B \& Forrest D. Mice devoid of all known thyroid hormone receptors are viable but exhibit disorders of the pituitary-thyroid axis, pituitary growth, and bone maturation. Genes and Development 199913 1329-1341.

12 Bassett JH, O'Shea PJ, Sriskantharajah S, Rabier B, Boyde A, Howell PG, Weiss RE, Roux JP, Malaval L, Clement-Lacroix P, Samarut J, Chassande O \& Williams GR. Thyroid hormone excess rather than thyrotropin deficiency induces osteoporosis in hyperthyroidism. Molecular Endocrinology 200721 1095-1107.

13 Mora S, Weber G, Marenzi K, Signorini E, Rovelli R, Proverbio MC \& Chiumello G. Longitudinal changes of bone density and bone resorption in hyperthyroid girls during treatment. Journal of Bone and Mineral Research 199914 1971-1977.

Received 13 April 2007

Accepted 25 May 2007 